\title{
A New Islanding Detection Technique Based on Passive Parameter using a Combination of Artificial Neural Network and Evolutionary Programming Algorithm
}

\author{
Hasmaini Mohamad, Aimie Nadia Ab Salam, Norhasniza Md Razali, Nur Ashida Salim, and Zuhaila \\ Mat Yasin
}

\begin{abstract}
To protect distributed generation (DG) from the harmful impact of islanding, DG connection codes worldwide require that all islanded DGs to be disconnected immediately after the formation of islanding. Islanding can be detected using three main types of detection techniques i.e local, remote and computational intelligent. The computational intelligence technique is the most recent approach that can produce almost zero non-detection zones. This paper presents the development of a new islanding detection technique for a synchronous-type DG based on the most sensitive passive parameters using the Artificial Neural Network (ANN)-Evolutionary Programming (EP). The most sensitive parameter was selected from 16 passive parameters using the sensitivity analysis. The analysis was conducted based on the response of each parameter when the test system was subjected with different types of islanding and non-islanding events. The selected parameter was then applied as an input for ANN-EP. EP was used to optimally tune the ANN parameter to accurately classify the islanding phenomenon. Large numbers of training and testing data sets were recorded from a simulation study that was conducted on an $11 \mathrm{kV}$ distribution test system. A performance comparison between ANN and ANN-EP in classifying islanding and non-islanding events was performed. The results showed that the ANN-EP had outperformed ANN in terms of accuracy of classification.
\end{abstract}

Index Terms-Artificial Neural Network, .Distributed Generations, Evolutionary Programming, Islanding, Passive Islanding Detection Technique.

\section{INTRODUCTION}

$\mathrm{D}$ ISTRIBUTED GENERATION (DG) can be defined as the generating resource apart from the main generating stations. DGs are often located at strategic locations near the load connected in the distribution network. DGs are usually connected in parallel to the main grid, and supply the required

This manuscript is submitted on 16th July 2020 and accepted on 28th December 2020. This work was supported by Universiti Teknologi MARA.

Hasmaini Mohamad, Aimie Nadia Ab Salam, Norhasniza Md Razali, Nur Ashida Salim and Zuhaila Mat Yasin are with the Faculty of Electrical Engineering, Universiti Teknologi MARA, 40450 Shah Alam, Malaysia (email: hasmaini@uitm.edu.my).

1985-5389/C 2021 The Authors. Published by UiTM Press. This is an open access article under the CC BY-NC-ND license (http://creativecommons.org/ licenses/by-nc-nd/4.0/). power to the local load and its surrounding area. DGs are used as the back-up power supply to improve the reliability in transmission and distribution system, while preventing the charges of network, minimising losses, slow down the development of large generation facilities, replacing the highpriced grid power generation, improving power quality, and minimising the peak loads [1]. The DG must be operated in a safe manner, whereby it has to supply the required power to loads in the presence of grid power supply. Nevertheless, the integration of DGs in the network poses some technical issues, which critically require particular attention. One of the issues faced by DG is the unplanned islanding event.

Islanding is a phenomenon where a section of the distribution system, which is integrated with DG, is disconnected from the main supply. However, the DG keeps supplying power to the load. Islanding may occur due to several situations, such as an unexpected disturbance in the distribution system, a failure in the grid that leads to a switch opening not detected by the protection device on the DG, intended disconnection for the maintenance services, and human error or vandalism [1]. Failure to detect islanding events can have negative impacts to the generator and the connected loads. According to IEEE 1547 standards, unintentional islanding must be detected within 2 seconds from failure time [2]. Therefore, an appropriate islanding detection technique is required to quickly identify its formation. Different techniques have been developed to detect the formation of islanding. These techniques can be divided into remote and local techniques. The local technique comprises of three main techniques, namely, passive, active, and hybrid.

Passive islanding detection technique is widely used in identifying islanding formation in distribution systems [3]. The main advantage of this technique is its low cost of operation and simplicity [4]. Therefore, the protection system would not require any major changes [5]. It does not disturb the parameters of the system and can efficiently detect islanding when there is a large imbalance between generation and demand in the system $[5,6]$. Single parameters, such as rate of change of frequency $(d f / d t)$ [7], change of harmonic impedance 
[8], and phase shift [9] are often used in a passive technique. Nonetheless, the disadvantages of using single parameters may include the large non-detection zone (NDZ) and low accuracy. Using two or more parameters can improve these problems. Examples of research conducted using combinations of parameters include rates of change of frequency and active power [10], total harmonic distortion and voltage unbalance [11], and rate of change of power factor and voltage [12].

For the active technique, disturbance is introduced at the output of the inverter-type DG to study the effect of the disturbance on the voltage, frequency, and impedance parameters. Islanding can be detected even under an accurate matching of generation and load (nearly zero NDZ). However, this technique introduces perturbation at regular intervals during most operation conditions, which can bring down the quality of the grid voltages and may even cause an imbalance [1]. The active technique would also take more time to detect the islanding phenomenon compared to the passive method [6]. The hybrid technique is based on a combination of the active and passive techniques. By combining these two methods, the hybrid technique can benefit from the advantages offered by both [13]. The active technique is used only when islanding is suspected by the passive technique [14].

Recent research claimed that islanding detection using the computational intelligent technique would have a better performance compared with other techniques by producing lower computational time and prediction errors. The computational intelligence technique mainly relates to a group of methods that mimic human intelligence [15]. This technique often apply the Artificial Neural Network (ANN) [16], Fuzzy Logic Control (FLC) [17], Evolutionary Programming (EP) [7][18], Adaptive Neuro Fuzzy Inference System (ANFIS) [19], and Decision Tree (DT) [20] to identify or classify islanding and non-islanding events. The technique based on these algorithms has the ability to solve non-linear multi-objective complications, which cannot be clarified using the general approaches, with the desired speed and accuracy [15]. Furthermore, the ability of these techniques to significantly reduce the non-detection zone has increased the interest of researchers to further improve the algorithm for islanding detection.

Nowadays, passive parameters, including indices and corresponding rate of changes, are employed in the computational intelligence technique to detect the formation of islanding. These parameters act as inputs to the classifier of the computational intelligence technique in different islanding and non-islanding cases. As in [21], 21 parameters, 14 indices, and 2 rates of change were applied to distinguish different events. There were 3 indices and 2 rates of change, as well as 13 indices and 14 rates of change that were applied as the inputs in [22] and [23], respectively. The application of multiple parameters will make the system more complex [10]. However, a higher number of adopted parameters would not guarantee that the detection would produce an accurate result. Only one or two parameters have the tendency to appropriately respond when the system is subjected to different types of disturbances. Thus, a selection of the most reliable and sensitive passive parameters for all disturbances is essential in ensuring a good detection technique. Research conducted in [24] has acquired the most sensitive parameter from 16 possible passive parameters tested for various islanding and non-islanding events in a distribution system.

This paper proposes a new islanding detection technique based on the most sensitive parameter obtained by [24] using the artificial neural network and the Evolutionary Programming (ANN-EP) technique. EP was used to optimally identify the suitable ANN parameters for ANN modeling. The training and testing data for the ANN-EP were selected from the measurement data for such parameters. Various islanding and non-islanding events were trained and tested to improve the performance of the islanding detection technique. Then, the kfold cross-validation performance analysis was conducted to validate the results obtained from the optimization technique.

\section{Methodology}

This section describes the methods used during the development of ANN-EP technique and the k-fold crossvalidation study. Fig. 1 shows the overall concept of the proposed islanding detection technique. The proposed technique has four main phases, namely, the development of measurement tools, the identification of sensitive parameters, the optimization technique, and the analysis of the k-fold crossvalidation. For the first phase, the measurements were taken at the point of common coupling (PCC) of a mini hydro DG. A total of 16 different passive parameters were measured under different conditions. The parameters are recorded in Table I. Power Systems Computer Aided Design (PSCAD) software was used to develop 16 measurement tools dedicated for compiling the data for the passive parameters. The measurements on the network system were subjected to several events, including loss of mains, fault cases, and load switching.

TABLE I

SIXTEEN DIFFERENT PASSIVE PARAMETERS

\begin{tabular}{cl}
\hline \hline No. & \multicolumn{1}{c}{ Passive Parameters } \\
\hline 1 & Rate of change of active power $(d p / d t)$ \\
2 & Rate of change of voltage $(d v / d t)$ \\
3 & Rate of change of reactive power $(d q / d t)$ \\
4 & Rate of change of frequency $(d f / d t)$ \\
5 & Rate of change of frequency over reactive power $(d f / d q)$ \\
6 & Rate of change of frequency over voltage $(d f / d v)$ \\
7 & Rate of change of active power over reactive power $(d p / d t)$ \\
8 & Rate of change of active power over voltage $(d p / d v)$ \\
9 & Rate of change of reactive power over frequency $(d q / d f)$ \\
10 & Rate of change of voltage over frequency $(d v / d f)$ \\
11 & Rate of change of voltage over reactive power $(d v / d q)$ \\
12 & Rate of change of reactive power over voltage $(d q / d v)$ \\
13 & Rate of change of active power over frequency $(d p / d f)$ \\
14 & Rate of change of frequency over active power $(d f / d p)$ \\
15 & Rate of change of reactive power over active power $(d q / d p)$ \\
16 & Rate of change of voltage over active power $(d v / d p)$ \\
\hline \hline
\end{tabular}




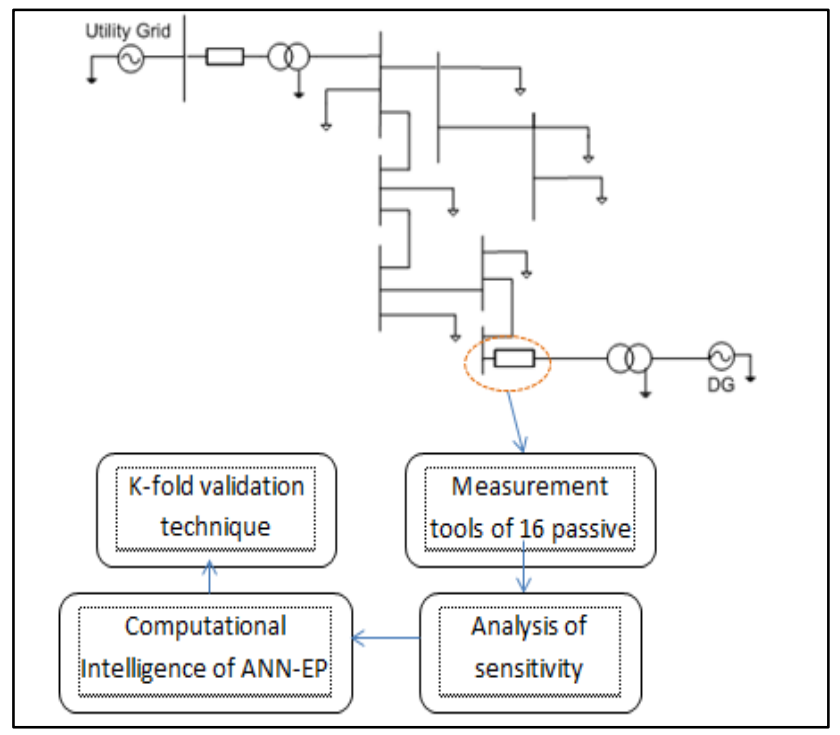

Fig. 1 Concept of the proposed islanding detection technique

In the second phase, the measurement data for each parameter was analysed in detail. The overall performance of each parameter for all events was evaluated based on its sensitivity towards islanding and non-islanding events. The sensitivity analysis is important in identifying the most suitable passive parameter that can clearly detect islanding and nonislanding events. The third phase was the most important part, where the islanding detection technique was developed using ANN-EP as the classifier. Data from the most sensitive passive parameter was used as the input for ANN. EP was used to optimally tune the suitable parameters of ANN in classifying the islanding events. The last phase was for analysing the k-fold cross-validation results, which can prove that the computational intelligence technique used in this research was able to produce an accurate result.

\section{A. Development of Islanding Detection Technique using Artificial Neural Network-Evolutionary Programming (ANN- EP)}

The ANN method is a popular solution for science and engineering problems, including for islanding detection. ANN is able to handle many non-linear relationships and can generalise solutions for new data sets [25]. An islanding detection technique using ANN was applied for two types of DGs, namely, the multiple inverter-based DG [26] and the hybrid inverter-based DG [27]. Different types of ANN, such as the self-organising map neural network [28], the extension neural network [29], and the modular probabilistic neural network [30] are applicable for islanding detection.

The performance criteria of ANN must be measured correctly. The first criterion in this study was the Root Mean Square Error (RMSE) between the targets and outputs of the neural network. The smaller the value, the better the performance of RMSE will be. The second criterion was the correlation coefficient (R-value). It was measured between the outputs and the targets in ANN. The output variable was valued between 0 and 1 . If the output number is closer to unity, the performance of the correlation coefficient is accurate, which is preferable. Meanwhile, if the output value is closer to 0 , this means that the correlation coefficient of the optimization is very poor. Therefore, a correlation coefficient with a higher value will give a better output response. The training time that ANN requires to complete the evaluation from beginning to the end of the process is also important to measure its performance. The lower time taken gives more accurate and better performance.

The combination of controllable factors will affect the performance of ANN. The controllable factors, as determined in this research, are as follows:

i. The percentage of training data:

First, the obtained data were categorised into training and testing sets. The training set was used for computing the gradient and updating the network weights and biases.

ii. The number of neurons in the first layer:

This factor was one of the most accurate parameters to determine the performance of ANN. In the computational analysis, more neurons were required to achieve an effective implementation.

iii. The number of neurons in the second layer:

This factor determined the number of neurons in the second layer, if the network has a second layer. However, if the parameter level is set at zero, the network would have only one hidden layer.

Although ANN can produce high detection accuracy, one of its drawbacks is that it can cause the algorithm to become more complex when using more parameters and data for storage [31]. To obtain the best performance of the ANN classifier, the parameters for ANN must be chosen properly and one of the solutions is to use the optimization technique [32]. Since it is tedious and time-consuming to determine the optimal values of the parameters by trial and error, ANN can be hybridized with EP to reach the optimal combination. Once the ANN-EP combination was used in this research, the learning process for obtaining the precise results became faster compared to using ANN alone. The aim in tuning ANN was to obtain the optimum combination of controllable factors that would improve the performance of ANN. Fig. 2 shows the process required for ANN-EP.

EP is a branch of the Evolutionary Computation (EC) technique that performs a semi-random search in optimizing an objective function. It uses a simple and direct method of representing the system parameters. It is also robust and able to reach global solutions. It comprises of several main processes, which are generation of random population, fitness evaluation, mutation, combination, selection, and the convergence test [33][34]. In this study, EP was designed to optimize the number of hidden nodes, the learning rate, and the momentum rate during the training process, thus, maximizing the value of prediction.

The fitness function of EP was set to be the R-value obtained during ANN tuning parameters. However, as ANN tuning parameters were very random and sometimes can be inconsistent, the average $\mathrm{R}$-value was introduced to provide a better indicator of the prediction performance. The average Rvalue was determined by summing all $\mathrm{R}$-values in the new generation pool before dividing the sum by the number of candidates in the pool. When the set of generated random 
numbers produced an R-value that violated the predetermined constraints, the overall random number generation process was repeated. Otherwise, the set of random numbers were placed in the pool population called parents.

After the pool population has been completely filled, the mutation process was conducted. The minimum and maximum

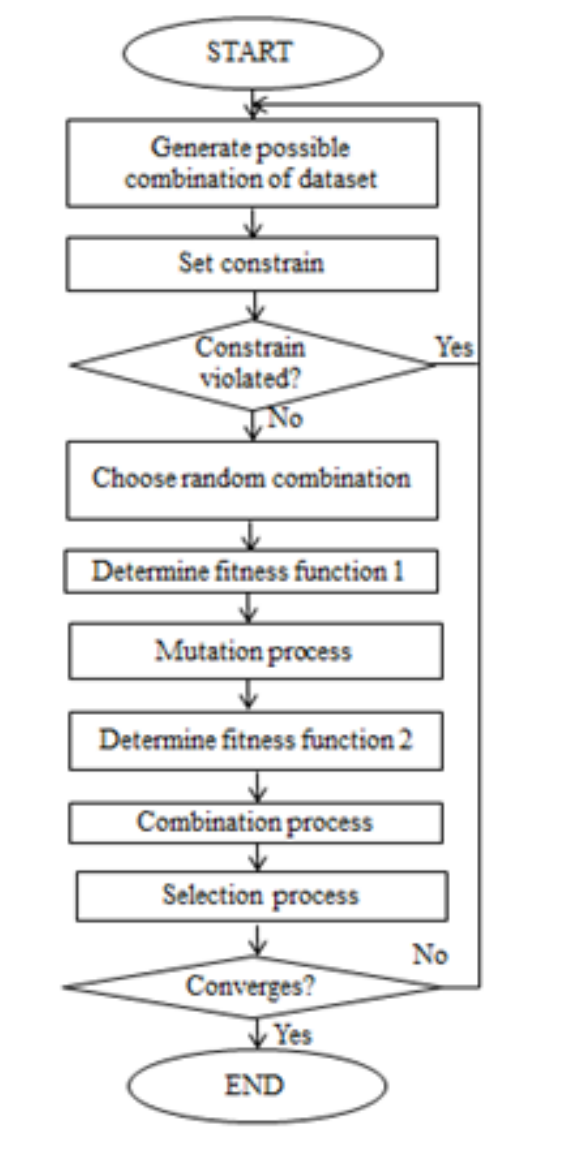

Fig. 2 Flowchart of the ANN-EP process

values of each random number in the pool population were initially computed. Then, the fitness function was calculated repeatedly using 20 sets of parents to produce $20 \mathrm{R}$-values. The maximum and minimum R-values were determined. Each parent set of random numbers underwent the mutation process using the Gaussian mutation expression, as shown in (1):

$$
\begin{aligned}
x_{i+m, j}=x_{i, j}+N & {\left[0, \beta\left(x_{j \max }\right.\right.} \\
& \left.\left.-x_{\text {jmin }}\right)\left(\frac{f_{i}}{f_{\max }}\right)\right]
\end{aligned}
$$

where,

$x_{i+m, j}=$ mutated individual

$x_{i, j}=$ current individual

$x_{\text {jmax }}=$ maximum value of $\mathrm{R}$ in a particular population

$x_{\text {jmin }}=$ minimum value of $\mathrm{R}$ in a particular population

$f_{i}=$ current fitness value

$f_{\text {max }}=$ maximum fitness value

The process was continued until 20 sets were obtained and each set was called an offspring. Next, both parents and offspring were combined to create a new population of 40 sets of numbers, with each of them having their own fitness value. The selection process proceeded with selecting and transcribing 20 sets of the highest fitness values as the new sets of random numbers for the next generation. Lastly, the convergence test was performed to obtain a robust islanding detection technique.

\section{B. Experimental Study based on K-Fold Cross-Validation Method}

Cross-validation is a method used for evaluating the results of a statistical analysis, which will be generalised to an independent data set [35][36]. There were two phases in this kfold cross-validation step, namely, training and testing for validation purposes.

The data generated from different cases of the islanding detection technique were separated into $\mathrm{k}$ numbers of folds. They were mutually exclusive to each other, but were of the same size, $\mathrm{P}=[\mathrm{P} 1, \mathrm{P} 2, \mathrm{P} 3, \ldots, \mathrm{Pk}\}$. K folds were used as training data, while k-1 folds were used as testing data. The completed procedure was iterated until each fold has been used [35]. The accuracy obtained with each iteration was then averaged to obtain the model accuracy. The accuracy of the classifier will be enhanced by employing optimization approaches.

\section{RESULTS AND DISCUSSION}

This research has adopted the test system of an existing 11 $\mathrm{kV}$ power distribution system in Malaysia, as shown in Fig. 3. The test system is modelled using the PSCAD simulation tools. It consists of two mini hydro DG resources, one biomass DG unit, 23 buses, and 21 lumped loads. The data for the load at every bus are tabulated in Table A (Appendix). The transformer is rated at $20 \mathrm{MVA}$ for $132 \mathrm{kV} / 11 \mathrm{kV}$ when connected to the grid system. Synchronous generators in the distribution side rated at 2 MVA each are connected to the 2 MVA rated transformer, which is used to step up the voltage from $3.3 \mathrm{kV}$ to $11 \mathrm{kV}$.

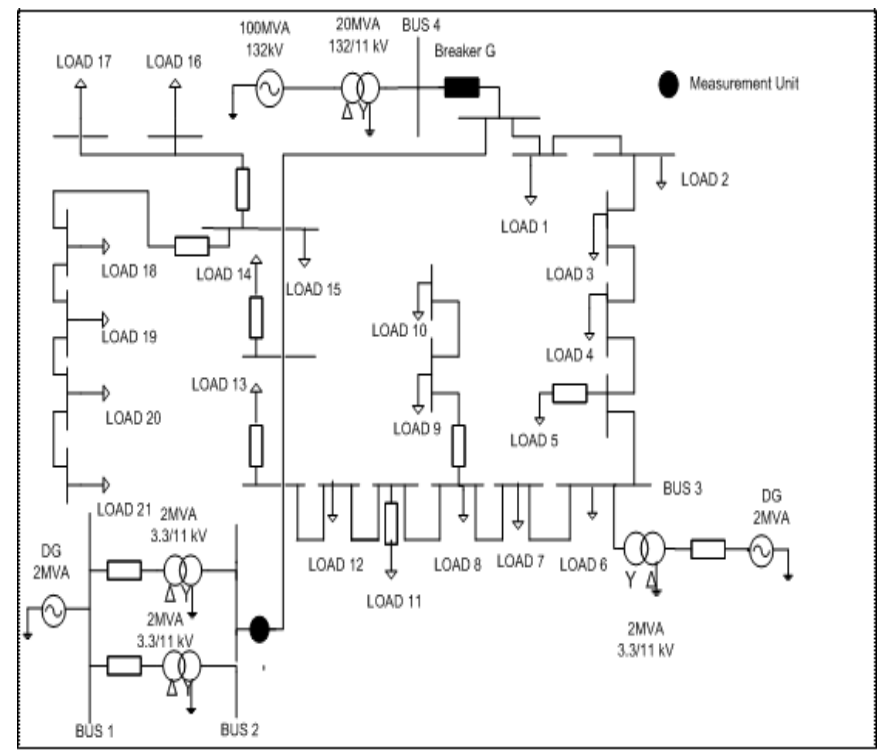

Fig. 3 Test System 


\section{A. The Most Sensitive Passive Parameters}

In determining the most sensitive passive parameters, all 16 parameters are tested in two categories of events, namely, islanding and non-islanding. Details of the measurement process and data analysis are presented in [24].

From [24], the sensitivity pattern for each parameter over the islanding and non-islanding events was first examined. The selection of the most sensitive parameter takes into consideration the higher magnitude of islanding or loss of the main event compared to the magnitude of non-islanding events.

Based on the results discussed in [24], the rate of change of frequency over active power $(d f / d p)$ is selected as the most sensitive compared to the other 15 parameters. This selection is made because all $d f / d p$ values in the simulated non-islanding cases are less than the $d f / d p$ values in islanding cases. Fig. 4 shows the magnitude of $d f / d p$ for islanding and non-islanding cases. Significant differences can be observed between islanding and non-islanding events for this parameter. Note that LOM is categorized as islanding whilst the other events are non-islanding type.

\section{B. ANN-EP Optimization Technique}

To produce an accurate intelligent classifier, a large number of islanding and non-islanding events were simulated in the test system. Data measurements for $d f / d p$ are recorded for each simulation case. Table II shows the list of cases used in the simulation study.

Different power mismatches between DG and the power consumed by the load for each bus were simulated for the islanding events. Power mismatch had ranged between $0 \%$ and $30 \%$, while $30 \%$ to $100 \%$ of the maximum power mismatch can be categorized as small and large power mismatches, respectively. The non-islanding events used in this research included load switching and fault cases at each bus.

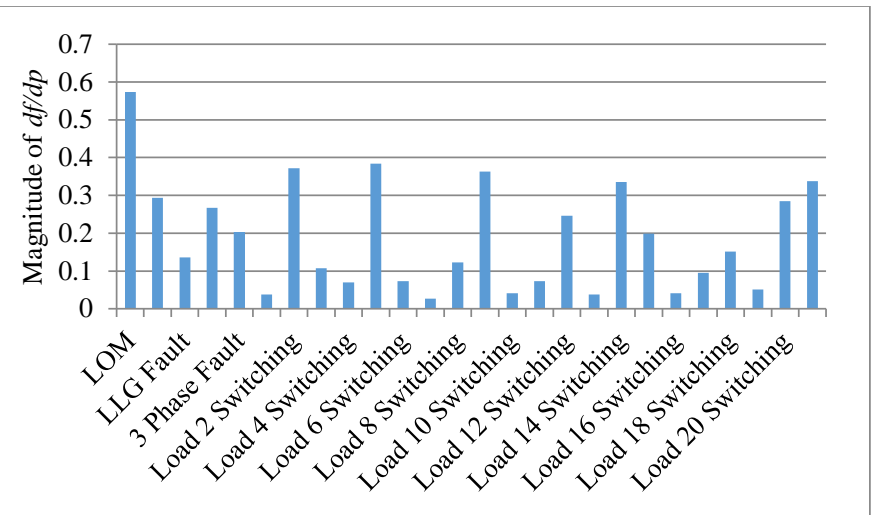

Fig. 4 Magnitude of $d f / d p$ in islanding and non-islanding cases
TABLE II

DESCRIPTIONS OF EVENTS AND CASES

\begin{tabular}{lll}
\hline \hline Events & Case Description & $\begin{array}{l}\text { Islanding } \\
\text { Status }\end{array}$ \\
\hline Islanding & $\begin{array}{l}\text { Small power mismatch at each bus } \\
(0-30 \% \text { of P and Q mismatch with a step } \\
\text { of 5\%) }\end{array}$ & 1 \\
Islanding & $\begin{array}{l}\text { Large power mismatch at each bus } \\
\text { (30-100\% of P and Q mismatch with a } \\
\text { step of 10\% })\end{array}$ & 1 \\
& \\
& $\begin{array}{l}\text { Load switching at each bus from 0.05 } \\
\text { MW and 0.05 Mvar to 1.0 MW and 1.0 }\end{array}$ & 0 \\
Non- & MVar with a step of 5\% \\
Non- & $\begin{array}{l}\text { Fault cases at each bus: } \\
\text { islanding } \\
\text { Line to ground fault } \\
\text { Line to line to ground fault } \\
\text { Line to line fault } \\
\text { Three-phase fault }\end{array}$ \\
\hline \hline
\end{tabular}

A total of 921 cases for different islanding and non-islanding events were simulated. This research created 419 cases of islanding events by taking into account different combinations of power mismatch of active and reactive power. The remaining 502 cases were non-islanding events, which included load switching and four different fault cases. After forming the data bank, 645 cases that represented $70 \%$ of the total cases are used for training and the remaining $30 \%$ or 276 cases are used for testing purposes. The selected islanding and non-islanding events for the testing data are classified into three groups, as listed in Table III. Group 1, Group 2, and Group 3 represent the data from buses $2-8$, buses $9-15$, and buses 16-22, respectively. The islanding and non-islanding events are further categorized into three sets.

A total of two indices of ANN are used to achieve acceptable classifier performance. The first analysis is conducted using the stand-alone ANN. The simulation is conducted by employing different numbers of hidden layers, momentum rates, number of neurons, and learning rates in ANN. The number of neurons is the first to be selected based on the trial and error method. The number of neurons in the first hidden layer is set to be two, while the number of neurons in the second hidden layer is eight. These values were selected due to the low value of regression obtained when the number of neurons was lower than two. The regression value is kept constant when the number of neurons used is higher than eight.

TABLE III GROUPING OF DATA FOR TRAINING AND TESTING

\begin{tabular}{llll}
\hline \hline Cases & Group 1 & Group 2 & Group 3 \\
\hline Islanding (419) & Testing & Training & Training \\
& Training & Testing & Training \\
& Training & Training & Testing \\
& Testing & Training & Training \\
& Training & Testing & Training \\
& Training & Training & Testing \\
\hline \hline
\end{tabular}


The second analysis is performed using ANN-EP, where EP is integrated with ANN to find the best parameters with high regression. To determine the best parameters for the learning rate and the momentum rate that would produce the value of $R$ close to unity, the value of both parameters is varied from 0.05 to 0.95, with 0.01 increment set in EP. Meanwhile, the number of neurons in the hidden layer is increased from two to 30 , with an increment of two, while the other parameters are kept constant. The objective function used in the study is based on the maximum regression value. Learning rate and momentum rate are varied by keeping one of them constant while the other is varied. ANN is trained with the optimal value acquired from EP.

The simulations for the stand-alone ANN and ANN-EP are repeated 10 times to determine the robustness of the technique and the two best sets of results are recorded. A comparison of the performance between the stand-alone ANN and ANN-EP is tabulated in Table IV.

TABLE IV

ANALYSIS OF ANN

\begin{tabular}{|c|c|c|c|c|}
\hline \multirow[t]{2}{*}{ ANN Indices } & \multicolumn{2}{|c|}{$\begin{array}{l}\text { Stand-alone Artificial } \\
\text { Neural Network }\end{array}$} & \multicolumn{2}{|c|}{$\begin{array}{l}\text { ANN-Evolutionary } \\
\text { Programming }\end{array}$} \\
\hline & Set 1 & Set 2 & Set 1 & Set 2 \\
\hline $\begin{array}{l}\text { Neurons in first } \\
\text { hidden layer }\end{array}$ & 2 & 2 & 2 & 2 \\
\hline $\begin{array}{l}\text { Neurons in } \\
\text { second hidden } \\
\text { layer }\end{array}$ & 8 & 8 & 27 & 16 \\
\hline Learning Rate & 0.05 & 0.06 & 0.83 & 0.59 \\
\hline Momentum Rate & 0.9 & 0.85 & 0.73 & 0.62 \\
\hline Regression (R) & 0.9378 & 0.9445 & 0.9689 & 0.9816 \\
\hline
\end{tabular}

Table IV shows that the number of neurons in the second hidden layer produced by ANN-EP is much higher than in the stand-alone ANN, whereby Set 1 and Set 2 produce 27 and 16 neurons, respectively. Similarly, the learning rate for ANN-EP is greater than for ANN. Apart from that, the momentum rate of ANN-EP is lower than ANN. Thus, the regression for ANN-EP is closer to unity compared with ANN. These results proved that ANN-EP is capable of producing a better classification of islanding compared to ANN.

\section{Data Evaluation and Analysis of K-Fold Cross-Validation}

The experimental results on 10 data sets for ANN-EP classifier and k-nearest neighbour showed that the independent assumption of fold accuracies was appropriate [37]. The crossvalidation of instances was the main factor for the dependence of their predictions. The data sets are used to find the average accuracy of the regression values, as shown in Fig. 5. The results obtained from the cross-validation technique were almost similar with the ANN-EP optimization technique. We observed that the minimum and the maximum values of regression were 0.9219 and 0.9820 , respectively of which proves that the regression of ANN-EP as in Table IV is within the range.

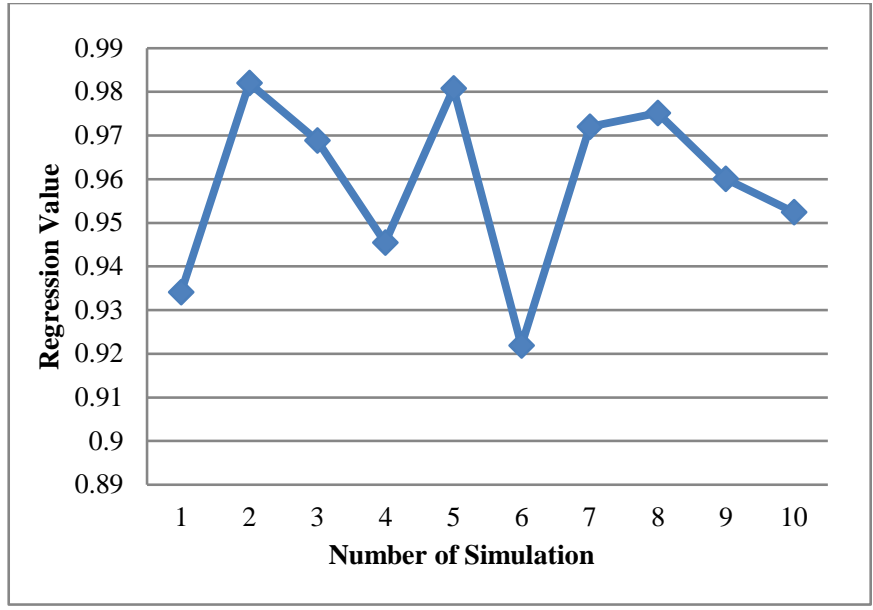

Fig. 5 Average Accuracy of Regression Value

\section{CONCLUSION}

This paper presents a new islanding detection technique based on the most sensitive passive parameter using ANN-EP algorithm. A comprehensive sensitivity analysis for 16 passive parameters by considering different types of disturbances (islanding and non-islanding) has identified the most sensitive passive parameter. The performance of $d f / d p$ was further analysed and it has shown that active power mismatch has an opposing effect on the variation of frequency $(d f)$ in real time environment. The measurement data for $d f / d p$ was then applied as the input data for ANN-EP classifier. As a result, the proposed detection technique has successfully classified islanding and non-islanding events. K-fold cross-validation was employed to validate the results obtained using the computational intelligence technique. The results showed that the average accuracy level was similar with the results produced by ANN-EP technique.

\section{REFERENCES}

[1] C. Trujillo, D. Velasco, E. Figueres, and G. Garcera, "Local and remote techniques for islanding detection in distributed generator," in Distributed Generators, D. N. Gaonkar (Ed.), IntechOpen, 2010, pp. 119-140.

[2] IEEE Standard for Interconnecting Distributed Resources into Electric Power Systems, IEEE Standard 1547TM, June 2003.

[3] G. Atreya and N. Gynawali, "Developing of islanding detection technique", in Proc. of IOE Grad. Conf., 2014, pp. 526-531.

[4] J. A. Laghari, H. Mohamad, A. H. A. Bakar, and M. Karimi.(2013, Dec.). A new islanding detection technique for multiple mini hydro based on rate of change of reactive power and load connecting strategy. Energy Conv. and Management. [Online]. (76), pp. 215-224. Available: https://doi.org/https://doi.org/10.1016/j.enconman.2013.07.033

[5] E. Kamyab and J. Sadeh. (2012, Dec.). Inverter based distributed generator islanding detection method using under/over voltage relay, Iranian Journal of Electrical \& Electronic Engineering.[Online]. 8(4), pp. 311-321. Available: http://ijeee.iust.ac.ir/article-1-522-en.pdf

[6] P. Mahat, Z. Chen and B. Bak-Jensen, "Review of islanding detection methods for distributed generation", in Proc. DRPT, Nanjing, China, 2008.

[7] H. H. Zeineldin and J. L. Kirtley. (2009, March). Performance of the OVP/UVP and OFP/UFP method with voltage and frequency dependent loads. IEEE Trans. on Power Delivery. [Online]. 24(2), pp. 772-778. Available: https://ieeexplore.iee.org/document/4803728

[8] M. Sumner, B. Palethorpe, D. W. P. Thomas, P. Zanchetta, and M. C. Di Piazza. (2002, March). A technique for power supply harmonic impedance estimation using a controlled voltage disturbance. IEEE Trans. 
on Power Electronics. [Online]. 17(2), pp. 207-215. Available: https://ieeexplore.ieee.org/document/988831

[9] G. - K. Hung, C. -C. Chang, and C. - L. Chen. (2003, Feb.). Automatic phase shift method for islanding detection of grid-connected photovoltaic inverters. IEEE Trans. on Energy Conversion. [Online]. 18(1), pp.169173. Available: https://doi.org/10.1109/TEC.2002.808412

[10] F. -S. Pai and S. -J. Huang. (2001, Dec.). A detection algorithm for islanding prevention of dispersed consumer-owned storage and generating units. IEEE Trans. on Energy Conversion. [Online]. 16(4), pp. 346-351.Available: https://ieeexplore.iee.org/document/969474

[11] H. Zeineldin and J. Kirtley, "A simple technique for islanding detection with negligible non-detection zone", in PES General Meeting, 2009.

[12] S. K. Salman, D. J. King, and G. Weller, "New loss of mains detection algorithm for embedded generation using rate of change of voltage and changes in power factors", in Int. Conf. on Developments in Power System Protection, 2001, pp. 82-85.

[13] M. G. M. Abdolrasol and S. Mekhilef, "Robust hybrid anti-islanding method for inverter-based distributed generation", TENCON, 2010, pp. 13-18.

[14] M. Mohiti, Z. Mahmoodzadeh, and M. Vakilian, "A hybrid micro grid islanding detection method", in EEEIC, 2013, pp. 342-347.

[15] J. A. Laghari, H. Mokhlis, M. Karimi, A. H. A. Bakar, and H. Mohamad.(2014, Dec.). Computational intelligence based techniques for islanding detection of distributed generation in distribution network: a review. Energy Conv. and Management.[Online]. 88, pp. 139-152. Available:https://doi.org/https://doi.org/10.1016/j.enconman.2014.08.02 4

[16] J. A. Laghari, H. Mokhlis, M. Karimi, A. H. A. Bakar, and A. Shahriari, "Artificial neural network based islanding detection technique for mini hydro type distributed generation, in CEAT, 2014, pp. 1-6.

[17] R. Eugeniusz, A. Burek, and L. Jedut, "A new method for islanding detection in distributed generation," (2007)

[18] D. Saxena, S. N. Singh, and K. S. Verma. (2010). Application of computational intelligence in emerging power systems. Int. Journal of Engineering, Science and Technology. [Online]. 2(3), pp 1-7. Available: https://www.ajol.info//index.php/ijest/article/view/59166

[19] H. Bitaraf, M. Sheikholeslamzadeh, A. M. Ranjbar, and B. Mozafarei, "Neuro-fuzzy islanding detection in distributed generation, in IEEE PES Innovative Smart Grid Techn., 2012, pp. 1-5.

[20] S. Yong and S. M. Rovnyak. (2004, March). Decision tree-based methodology for high impedance fault detection. IEEE Trans. Power Deliver. [Online]. 19(2), pp. 533-536. Available: https://doi.org/10.1109/TPWRD.2003.820418

[21] O. N. Faqhruldin, E. F. El-Saadany, and H. H. Zeineldin.(2014, June). A universal islanding detection technique for distributed generation using pattern recognition, IEEE Trans. on Smart Grid. [Online]. 5(4), pp.19851992. Available: https://doi.org/10.1109/TSG.2014.2302439

[22] M. R. Alam, K. M. Muttaqi, and A. Bouzerdoum.(2014, Jan.). An approach for assessing the effectiveness of multiple-feature-based SVM method for islanding detection of distributed generation. IEEE Trans. on Ind. Apps. [Online]. 50(4), pp. 2844-2852. Available: https://doi.org/10.1109/TIA.2014.2300135

[23] S. Kar and S. R. Samantaray.(2014). Data-mining-based intelligent antiislanding protection relay for distributed generations. IET Generation, Transmission \& Distribution.[Online]. 8(4), pp. 629-639. Available: https://doi.org/10.1049/iet-gtd.2013.0494

[24] A. N. A. Salam, H. Mohamad, N. Y. Dahlan, and S. Raza.(2017, Sept.). Performance of multiple passive islanding detection technique for synchronous type of DG. Journal of Electrical Systems, 13(3), pp. 568578.

[25] D. Hammerstrom. (1993, June). Neural network at work. IEEE Spectr.[Online]. 30(6), pp. 26-32. Available: https://doi.org/10.1109/6.214579

[26] Y. Fayyad and A. Osman, "Neuro-wavelet based islanding detection technique", in Proc. IEEE EPE, 2010, pp. 1-6.

[27] M. S. ElNozahy, E. F. El-Saadany, and M. M. A. Salama, "A robust wavelet-ANN based technique for islanding detection", in Proc. IEEE PESGM, 2011, pp. 1-8.

[28] A. Moeini, A. Darabi, S. M. R. Rafiei, and M. Karimi.(2011, Feb.). Intelligence islanding detection of a synchronous distributed generation using governor signal clustering. Electrical Power Sys. Res. [Online]. 81(2), pp. 608-616. Available: https://doi.org/https://doi.org/10.1016/j.epsr.2010.10.023

[29] M. H. Wang, M. -L. Huang, and K. -J. Liou. (2015, Aug.). Islanding detection method for grid connected photovoltaic systems. IET Renew.
Power Gen. [Online]. 9(6), pp. 700-709. Available: https://doi.org/10.1049/iet-rpg.2014.0264

[30] S. R. Mohanty, P. K. Ray, N. Kishor et al. (2013, Jan.). Classification of disturbances in hybrid dgs system using modular PNN and SVM. Int. Journal Electric Power.[Online] 44(1), pp. 764-777. Available: https://doi.org/https://doi.org/10.1016/j.ijepes.2012.08.020

[31] S. Raza et al.(2016) Minimum-features-based ANN-PSO approach for islanding detection in distribution system. IET Renewable Power Generation. [Online]. 10(9), pp. 1255-1263. Available: https://doi.org/10.1049/iet-rpg.2016.0080

[32] H. A. Ilias, X. R. Chai, A. H. A. Bakar, and H. Mokhlis. (2015, June). Transformer incipient fault prediction using combined artificial neural network and various particle swarm optimization techniques. PLOS ONE. [Online]. $10(6), \quad$ pp. $1-16 . \quad$ Available: https://doi.org/10.1371/journal.pone.0129363

[33] S. N. Sivanandam, S. Sumathi, and S. N Deepa, Introduction to Neural Networks using Matlab 6.0, New Delhi: Tata McGraw Hill, 2006.

[34] T. Back, I. Centrum, and H. -P. Schwefel, "Evolutionary computation: an overview", in IEEE ICEC, 1996, pp. 20-29.

[35] S. S. S. Rawat, V. A. Polavarapu, and V. Kumar, "Anomaly detection in smart grid using rough set theory and $\mathrm{K}$ cross validation", in ICCPCT, 2014.

[36] J. G. Moreno-Torres, J. A. Saez, and F. Herrera. (2012, Aug.). Study on the impact of partition-induced dataset shift on k-fold cross-validation. IEEE Trans. on Neural Networks and Learning Systems. [Online]. 23(8), pp. 1304-1312. Available: https://doi.org/10.1109/TNNLS.2012.2199516

[37] V. L. Merlin, R. C. Santos, A. P. Grilo, J. C. M. Vieira, D. V. Coury, and M. Oleskovicz.(2016, Feb.). A new artificial neural network based method for islanding detection of distributed generators. IJEPES.[Online]. 75, pp. 139-151. Available: https://doi.org/10.1016/j.ijepes.2015.08.016

\section{APPENDIX}

TABLE A

LOAD DATA

\begin{tabular}{lll}
\hline \hline Load & Active power (MW) & Reactive power (MVar) \\
\hline 1 & 0.1635 & 0.1255 \\
2 & 0.099 & 0.0615 \\
3 & 0.15 & 0.0498 \\
4 & 0.10485 & 0.07375 \\
5 & 0.01475 & 0.0095 \\
6 & 0.0744 & 0.04335 \\
7 & 0.145 & 0.0476 \\
8 & 0.15 & 0.0339 \\
9 & 0.04785 & 0.02115 \\
10 & 0.03975 & 0.02475 \\
11 & 0.10605 & 0.0657 \\
12 & 0.1039 & 0.0558 \\
13 & 0.0228 & 0.0141 \\
14 & 0.21 & 0.1755 \\
15 & 0.03075 & 0.00975 \\
16 & 0.01965 & 0.02985 \\
17 & 0.10675 & 0.0589 \\
18 & 0.06715 & 0.044 \\
19 & 0.0751 & 0.0495 \\
20 & 0.0265 & 0.02075 \\
21 & 0.1734 & 0.074 \\
\hline \hline
\end{tabular}




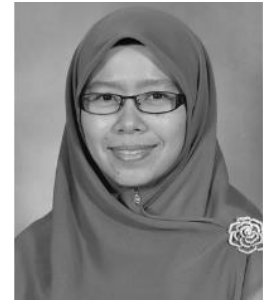

Hasmaini Mohamad received the B.Eng., M.Eng., and Ph.D. degrees from the University of Malaya, in 1999, 2004, and 2013, respectively. She started her career as a lecturer in Universiti Teknologi MARA in 2003 where currently she is an Associate Professor at the Centre for Electrical Power Engineering Studies, Faculty of Electrical Engineering. Apart from that, she has published more than 50 journal papers including high impact ISI journals and 20 conference papers. Her major research interest includes islanding operation of distributed generation, hydro generation, load sharing technique, and load shedding scheme.

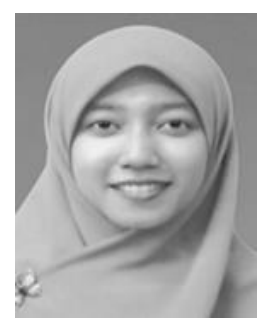

Aimie Nadia Ab Salam borned at Hospital Besar Tawau, Sabah in $11^{\text {th }}$ August 1991. She obtained Bachelor of Electrical Engineering (Hons.) Power from Universiti Teknologi MARA, Shah Alam, Selangor, Malaysia in 2014 and completed her MSc in Science from Universiti Teknologi MARA at Faculty of Electrical Engineering in 2019. Currently she is working as Part Time Lecturer in University Teknologi MARA, Shah Alam. Her research interests are islanding detection method, power system distribution and computational intelligence optimization technique.

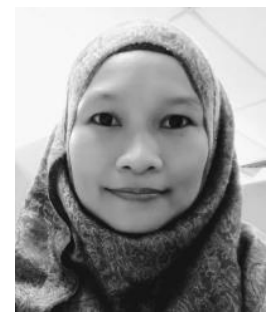

Norhasniza Md Razali was born in Kelantan, Malaysia in 1983. She received the B.Sc. degree in electrical engineering from University of Science, Malaysia, in 2006 and the M.Sc. degree in engineering from University of Malaya, Malaysia in 2012. She is currently pursuing the Ph.D. degrees in electrical engineering at University of Teknologi MARA, Malaysia. From 2012 to 2015, she was a Research Assistant with the UM Power Energy Dedicated Advanced Centre, University of Malaya, Malaysia. From 2016 to 2017, she was a lecturer with the University of Tenaga Nasional, Malaysia. Her research interests include power system, smart grid and artificial intelligence.

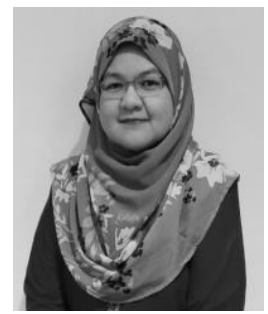

Nur Ashida Salim received her $\mathrm{PhD}$ in Electrical Engineering from Universiti Teknologi MARA in 2015, Master in Engineering (Power System \& Electrical Energy) from Universiti Malaya in 2006 and Bachelor in Electrical Engineering (Hons.) from Universiti Teknologi MARA in 2003. She is currently an Associate Professor at the Centre for Electrical Power Engineering Studies, Faculty of Electrical Engineering, Universiti Teknologi MARA. Her research includes power system reliability, power system planning, power system stability, power system asset management and other related areas. To date, she has published more than 40 journal articles and many proceeding papers.

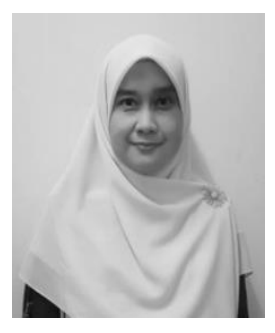

Zuhaila Mat Yasin graduated from Universiti Sains Malaysia with honours degree in Electrical and Electronics Engineering in 1998. She obtained her MSc degree in 2008 and $\mathrm{PhD}$ degree in 2015 from Universiti Teknologi MARA. She is currently a senior lecturer at Universiti Teknologi MARA. Her research interest includes power system operation, optimization, distributed generation, Artificial Intelligence and smart grid system. 